I Universidade do Estado do Rio de Janeiro,

Departamento de Antropologia, Rio de Janeiro, RJ, Brasil

mccoelho@bighost.com.br

https://orcid.org/0000-0003-3885-5429

I I Universidade Federal do Rio de Janeiro,

Departamento de Sociologia, Rio de Janeiro, RJ, Brasil

eduardomoura@gmail.com

https://orcid.org/0000-0002-3778-7199

Maria Claudia Pereira Coelho'

Eduardo Moura Pereira Oliveira"

\title{
REFLEXÕES SOBRE O TEMPO E AS \\ EMOÇÕES NA ANTROPOLOGIA: \\ DEFINIÇÕES, PRÁTICAS E POLÍTICAS ${ }^{1}$
}

Hope is never far away from nostalgia.

David Berliner (2015)

Este texto examina formas de compreender a relação entre emoções, temporalidade e política. Trabalho de natureza exploratória, seu propósito principal é articular a análise antropológica de dois sentimentos - a nostalgia e a esperança - com o objetivo de construir um arcabouço conceitual para examinar, sob o prisma da antropologia das emoções, fenômenos políticos tais como as formas de atuação em movimentos sociais e em disputas eleitorais, tomadas como um momento em que as vivências subjetivas do passado e do futuro são ressignificadas no tempo presente.

A articulação aqui proposta nos permite realizar um duplo movimento, no sentido de compreender as dinâmicas emocionais relacionadas às formas de sentir o passado, o presente e o futuro como construções culturais não universalizáveis, mas tributárias de configurações sociais e políticas; e os sentimentos não confinados ao íntimo do sujeito, mas antes capazes de orientar a vida dos indivíduos, mobilizando práticas e alimentando expectativas.

O artigo se insere, assim, na área da antropologia das emoções, avançando no exame do trabalho realizado pelas emoções em fenômenos da vida pública. A fecundidade teórica dessa orientação analítica para o estudo de fenômenos como o policiamento, os movimentos sociais e os universos profissionais já foi discutida por nós em outros trabalhos (Coelho \& Durão, 20I7) e explorada em campos específicos, como a vitimização em situações de violência (Coelho, 20I0), o exercício da autoridade policial (Coelho et al., 20I3) e a experiência do exílio (Oliveira, 20I8). 
É incontestável que toda experiência emocional apresenta uma dimensão temporal, no sentido de sua duração - como, por exemplo, na percepção de um amor como "eterno" ou na descrição de uma amizade como "de infância" - ou de sua relação com momentos específicos - a tristeza desencadeada por ritos funerários, para voltar ao exemplo canônico de Mauss (I980). Há, contudo, algumas emoções cuja essência reside na forma específica de relação com o tempo que entretêm, seja pela percepção de sua "passagem", seja pelo vínculo que estabelecem entre a subjetividade e o passado, o presente e o futuro.

Assim, por exemplo, o tédio e a ansiedade se definem como uma forma de relação com o presente, em que o sujeito se vê diante de um tempo "que não passa", uma espécie de presente eterno, com a diferença se dando pelo efeito subjetivo desse "excesso de presente", apático e resignado no primeiro caso, aflito e desejoso de libertação no segundo. Esperança e medo, por sua vez, entabulam uma relação com o futuro marcada ora pelo otimismo, ora pelo pessimismo; ora pelo engajamento, ora pela paralisia. E ressentimento, saudade, remorso e nostalgia jogam com o passado, expondo modos subjetivos de lidar com aquilo que é percebido como não existindo mais, sejam perdas, derrotas, fracassos ou conquistas, vitórias, sucessos.

Como as lembranças de um passado revivido orientam práticas e discursos? Como as esperanças e projeções no futuro convocam ações no presente? Tais perguntas permitem ligar o estudo do tempo e das emoções a uma dimensão política, uma vez associado a expectativas de transformação social, tal como é possível observar nos discursos políticos de candidatos e mesmo nos acontecimentos de 2013 que ficaram conhecidos no Brasil como Jornadas de junho, quando uma série de manifestações ganhou corpo e se alastrou por diversas cidades do país. Nessas falas, o acionamento e a evocação da esperança como nutriente da ação, sejam motivados por fins eleitorais ou inspirados por princípios de justiça e equidade, ocupam lugar central no direcionamento discursivo de atores, ainda que no tabuleiro da política suas posições sejam distintas.

$\mathrm{O}$ artigo discute o deslocamento das subjetividades das realidades mais imediatas, abordando modalidades de se viver, reviver e antecipar o tempo. Sua natureza é de uma pesquisa bibliográfica que toma por objeto dois textos de antropólogos articulados de acordo com um ângulo específico: a abordagem das relações entre a passagem do tempo e uma gramática dos sentimentos, de modo a ressignificar experiências do passado e expectativas do futuro. A exploração da relação entre emoções e temporalidade tomará aqui como foco dois sentimentos descritos na literatura como entretendo relações com o tempo capazes de engendrar formas de atuação política: a nostalgia e a esperança.

A exposição está estruturada em duas seções: nostalgia, percepção do passado e projetos políticos, com base em texto de David Berliner (2015); e esperança, percepção do futuro e engajamento político, com base em texto de 
Vincent Crapanzano (2004). Nas considerações finais, esboçamos algumas sugestões relativas à fecundidade analítica do instrumental conceitual aqui delineado, procurando elaborar dois pontos: de que maneira as fronteiras entre passado e futuro podem ser esmaecidas pela vivência subjetiva desses momentos; e de que modo a relação entre emoções e tempo pode orientar a construção de arcabouços conceituais para a análise de fenômenos políticos contemporâneos, tais como os movimentos sociais, a propaganda política eleitoral e o exílio.

\section{NOSTALGIA E ESPERANÇA}

Entre as características da vida moderna, a noção da passagem do tempo se estabelece na consciência como uma sequência de acontecimentos ordenados a partir de uma realidade presente e dividida entre as experiências do passado e as expectativas do futuro. Implica processos subjetivos de revitalização do que foi e de projeção do que virá, num deslocamento afetivo descompassado com a ideia de tempo enquanto fluxo contínuo e regular da vida.

Imagens desse descompasso figuram mediante dois sentimentos inscritos no tempo: a nostalgia, revivescência do passado, e a esperança, desabrocho ao futuro. Com base no pressuposto das discrepâncias entre o tempo objetivo e a experiência subjetiva, discutimos a seguir essas dimensões, tomando como referência as teses de David Berliner e Vincent Crapanzano.

\section{O TEMPO DO "TARDE DEMAIS": A NOSTALGIA E OS CONFINS DA PERDA}

Nostalgia é o sentimento de perda inscrito no fluxo do tempo. A origem do termo se desmembra no grego nostos, no sentido de "retorno ao lugar de origem, ao ponto inicial" e algos, que significa "dor, tristeza" em relação ao ausente. Entre os gregos, nostalgia refere-se a um estado de perturbação ou inquietação característico daqueles que realizavam longas viagens e se viam tomados pela lembrança do que estava distante. Assim, nostalgia aparece como um sentimento voltado para o ponto inicial, baseado na vivência subjetiva da continuidade de um passado reativado pela memória e que persiste em vigor no presente.

Segundo Olivia Angé e David Berliner (2015), no livro Anthropology and nostalgia, o pressuposto a partir do qual a nostalgia pode ser pensada como categoria das ciências sociais é o da irreversibilidade do tempo. Os autores consideram a irregularidade rítmica entre as transformações sociais e as vivências subjetivas para expor o contraste entre um tempo que se projeta ao futuro e um sentido de preservação das bases que serve de referência aos rumos da cultura e da política. Enquanto o espírito moderno finca raízes em uma razão voltada para o progresso, a reação nostálgica é a percepção da permanência da própria identidade e a sensação de morte de um passado que não pode ser revivido.

Cabe às ciências sociais compreender como os indivíduos lembram, comemoram e revitalizam seu passado à luz de regras sociais que operam sobre 
a nostalgia. Angé e Berliner (20I5) exploram a relação entre as ciências sociais e a produção de diagnósticos da perda. Posto que as análises do presente tomam como referência uma época anterior, tendem a se tornar sensíveis ao que se perdeu no passado ou que está em vias de se perder no presente, seja pelas constantes transformações provocadas no contexto da formação das metrópoles, seja pelo risco do contato entre diferentes culturas de modo a favorecer a permanência de uma em detrimento das outras.

Na sociologia, os diagnósticos sobre a perda tomam como referência os processos de urbanização e industrialização para opor tradição e modernidade, operando a partir da comparação entre épocas. De acordo com Angé e Berliner (20I5: 3), teorias como as de Émile Durkheim, Max Weber, Ferdinand Tönnies e Georg Simmel guardam em si posturas críticas em relação à emergência de uma sociedade industrial capaz de estabelecer uma oposição entre o tradicional e o moderno em termos de degradação social. Na antropologia, a preocupação com o risco de desaparecimento e o desejo de transmissão cultural do "outro distante" característico das culturas "tradicionais" assumiu a forma de retóricas permeadas por um senso de devastação em relação à vida daquela cultura no passado. Ao entrar em contato com as culturas locais, a postura colonizadora das sociedades europeias representava uma ameaça ao sentido de preservação, preocupação que inspirou, entre os antropólogos, sentimentos e discursos sobre a perda do outro, o que marcaria certa postura nostálgica nos primeiros trabalhos. As etnografias de Bronislaw Malinowski, Edward Evans-Pritchard, Franz Boas e Marcel Griaule expressam essa posição, entre muitas outras. É o que David Berliner chamou de exo-nostalgia (20I5: 4), um passado vivido pelo outro, ao contrário da endo-nostalgia, que trata de um passado vivido pessoalmente (20I5: 2I).

Angé e Berliner identificam a partir dos anos I960 a emergência de uma cultura da nostalgia, com o crescimento das mídias e das técnicas de comercialização. O surgimento de temas cuja orientação estava voltada para o passado, tais como as técnicas de parto natural, o consumo de comidas orgânicas e a apreciação de uma estética retrô no design e na cultura, aparecia como formas contemporâneas de nostalgia. Por sua vez, na política, assim como o Holocausto e as ditaduras latino-americanas representam um marco para os estudos da memória, o fim do socialismo e o mundo pós-I989 se tornaram um paradigma para os estudos da nostalgia (Angé e Berliner, 20I5: I).

A questão lançada por Berliner no texto que abre o livro - Os antropólogos são nostálgicos? - permite identificar duas dimensões do estudo da nostalgia do ponto de vista das ciências sociais. O primeiro corresponde a um esforço de transmissão e preservação das identidades e das tradições, uma atitude intelectual subjacente ao trabalho de pesquisadores, a antropologia como nostalgia. Paralelamente, a nostalgia se abre como campo de investigação, sendo unidade analítica a partir da qual é realizado o estudo de determinada cultura, nesse caso, a antropologia da nostalgia. 
Em relação à composição da obra, Angé e Berliner (20I5: I I) organizam os nove artigos a partir de quatro pontos capazes de ordenar os estudos da nostalgia: o caráter polissêmico da nostalgia e a sua capacidade de gerar variados investimentos cognitivos e emocionais a partir de seu significado; a compreensão de como as nostalgias são construídas dentro de contextos políticos e culturais; o nexo entre o sentimento e a ação, aspecto que considera a capacidade transformadora de práticas nostálgicas associadas a posturas e discursos políticos; e a forma como a nostalgia não se restringe a uma temporalidade inscrita no passado, mas, ao contrário, constitui-se em um sentimento capaz de se lançar a esperanças no futuro e dar sentido à vida no presente.

Expostas as dimensões de um estudo das vivências subjetivas voltadas para o tempo do "tarde demais", ${ }^{2}$ podemos situar a nostalgia à luz de tempos múltiplos. Sendo a nostalgia o tempo da vivência perdida e irreversível, o que revela um traço de universalidade marcada pelo crivo do tempo, podemos nos perguntar sobre os modos particulares de construção do tempo, desse modo de sentir o passado como algo que escoa irresistível ao longo da vida.

\section{O TEMPO DO "AINDA NÃO": A ESPERANÇA E OS HORIZONTES DO POSSÍVEL}

Em texto no qual discute diversas teses sobre a esperança, provenientes de áreas de conhecimento variadas (teologia, sociologia, psiquiatria, filosofia), Vincent Crapanzano (2004: 98) se propõe a abordar a esperança simultaneamente como categoria de análise e de experiência. Seu ponto de partida é o desequilíbrio entre a enorme atenção dada à esperança na teologia e o lugar desse sentimento nas ciências sociais. Uma pista inicial seria o lugar da esperança e do medo como bases sobre as quais se assentaria a vida religiosa, em oposição ao consumismo da vida moderna (berço da sociologia), com sua ênfase no imediatismo da gratificação e consequente dificuldade com o "tempo de espera" que caracterizaria a esperança.

O texto é estruturado em diversas seções que trazem, cada qual, as reflexões sobre a esperança provenientes de autores representativos de suas áreas disciplinares. Do conjunto, é possível abstrair um leque de questões que compõem uma verdadeira "agenda de pesquisa" sobre a esperança, tais como a relação entre esperança e desejo; a dimensão de certeza/dúvida quanto à viabilidade do almejado; a estrutura temporal na qual a esperança se insere; e a capacidade da esperança de impelir à ação ou, ao contrário, substituí-la, gerando paralisia.

No diálogo com a teologia, Crapanzano (2004: I03) focaliza a diferença entre esperança e expectativa expondo o conceito de "esperança verdadeira", definida como aquela que comporta a crença na certeza do que virá: "a 'esperança verdadeira', não importa o quão urgente, ou a crença nela depositada, ou o conforto que oferece pode fomentar uma retórica de desvio com enorme potencial econômico e político". ${ }^{3}$ 
Na psiquiatria, Crapanzano vai buscar na obra de Eugène Minkowski uma reflexão sobre a estrutura da experiência temporal na qual a esperança se baseia. Ela se situaria no tempo do "futuro mediado", aquele que se insere entre o "futuro imediato" - tempo da expectativa e da atividade - e o futuro remoto - tempo das orações.

O problema da relação entre sentimento e tempo é também o que Crapanzano (2004: I II) explora na sociologia de Ernst Bloch - aqui, a esperança seria o tempo do "ainda não", de uma temporalidade que olha para a frente: "Ele [Ernst Bloch] argumenta que todos vivemos no futuro porque nos esforçamos. As coisas do passado só vêm mais tarde. Um 'presente genuíno' quase nunca está lá". O futuro, contudo, não é um tempo exclusivo da esperança: o medo encontraria nele também sua temporalidade.

Com base em sua etnografia junto aos brancos sul-africanos nos últimos anos do apartheid, Crapanzano aborda o tema da relação entre esperança e ação, afirmando ter encontrado ali, na vivência daqueles que aguardavam o fim do apartheid apavorados com o que os aguardava, uma "paralisia induzida pela espera". Em suas palavras:

Eles não podiam se imaginar fora da situação em que se encontravam. Mesmo que tivessem uma solução, o que não tinham (ao menos não que pudessem levar a sério), não podiam agir com base nela. Eles simplesmente esperavam. Estavam aprisionados na estrutura da espera. Aquilo em que tinham esperança era em uma solução - algo que não conseguiam vislumbrar. Sua esperança era tão indefinida, que não conseguiam transformá-la em um desejo efetivo" (Crapanzano, 2004: I I5).

Os entrevistados de Crapanzano sabiam o que queriam - preservar sua riqueza e seu status quo -, mas sabiam também que isso não era possível. Seu antigo status quo estava, por certo, idealizado: segundo Crapanzano (2004: I I5), estava "repleto de nostalgia".

Essa esperança estava também atrelada ao medo, que, por sua vez, intensificava a paralisia, o estado de espera, ao qual Crapanzano (2004: I I6) se refere como uma "esperança adoecida": trata-se de um "campo do desejo em espera".

Nesse contexto, a esperança aparece atrelada a dois outros sentimentos: medo e nostalgia. Com o medo, esboça futuros possíveis. Com a nostalgia, imagina uma ponte entre o passado e o futuro que tinge a subjetividade do presente. Orienta, assim, a inação, a paralisia, nessa combinação entre um passado idealizado a cuja perda se está resignado e um futuro entrevisto como ameaçador.

O trabalho de Crapanzano inscreve a faculdade imaginativa no debate a respeito do estatuto do real presente nos trabalhos etnográficos. Diante de uma antropologia voltada para o literalismo, inscrita no paradigma semiótico fincado nas práticas interpretativas, edificado por Clifford Geertz, introduz o debate corrente acerca dos limites, das travessias e dos diálogos entre realidades distintas. Inspirado pela imagem do poeta francês Yves Bonnefoy a respei- 
to de uma zona continente posicionada geograficamente atrás dos litorais e das zonas de fronteira, Crapanzano (2004: 2) considera a hinterland (interior, em tradução livre) como a área de influência, a zona econômica que fornece mercadorias aos portos e fomenta o transporte marítimo. Hinterland, palavra que denota provincianismo, isolamento e atraso, é tomada pelo autor pelo sentido do que "está atrás", "a paisagem de fundo". o ponto reside na relação entre o íntimo e o horizonte, entre o plano de fundo e a figura, entre o interior e a borda. As fronteiras são horizontes que se estendem a partir de um aqui-agora, uma experiência ora dolorosa, ora prazerosa, realidade insistente perturbada pela possibilidade. Trata-se de um terreno imaginativo e fantasioso sobre o qual repousam as expectativas e as projeções de mundo.

No centro do debate entre tempo e sentimentos, importa a consideração do modo de vida pelo qual as pessoas compreendem suas experiências à luz de suas possibilidades. Trata-se de tomar como objeto de investigação a experiência subjetiva do presente que repousa sobre as chances de realização daquilo que se deseja ou daquilo que pode acontecer, uma vez diante de um horizonte temporal, factível ou não. Por esse prisma, as emoções no tempo poderiam ser pensadas pelos limites entre o aqui-agora e o que está além, um horizonte que influencia profundamente o modo como experimentamos o mundo.

Crapanzano aponta para os papéis desempenhados pela imaginação e pela criatividade enquanto fronteira entre realidade e possibilidade. O autor se dedica ao estudo das disjunções e seus paradoxos, buscando pensar em como inauguramos e damos por encerradas determinadas etapas da vida, de modo a organizar diferentes momentos e fases. A partir das considerações sobre o tempo aqui apresentadas, é possível pensar em momentos que se reduzem, mas nunca desaparecem por completo: "Em cada cruzamento há sempre um momento em que não se está nem em um lado nem no outro, em que não se é nem o que se era nem o que se será; pois, uma vez que duas coisas são discriminadas, o que é contíguo nunca chega a se tocar realmente" (Crapanzano, 2005: 6I).

Crapanzano reflete sobre o que está entre o real e o possível, momento da passagem que não pode ser enunciado; a travessia e os desafios impostos pelas separações, pelo movimento disjuntivo que vai de um estado a outro. O percurso teórico no qual Crapanzano se inscreve considera os momentos subjetivos inclassificáveis, limites entre estados íntimos que se constituem como fronteiras de passagens a novos estados.

\section{CONSIDERAÇÕES FINAIS}

Em outro lugar (Coelho, 20Io), discutimos a importância de estudar as formas como as emoções se articulam entre si, formando complexos emocionais, como no caso do amor e do ciúme. É essa a perspectiva adotada por Katz (20I3) para examinar a dinâmica entre humilhação e raiva presente em cenas de homicídios, em que a agressão física aparece, aos olhos do agressor, como 
a única alternativa para se livrar do sentimento de humilhação provocado por sua leitura dos atos e palavras da futura vítima como colocando em xeque valores essenciais para sua autoimagem (alcunhados por Katz de "bem supremo"). A mesma perspectiva orienta a discussão de Coelho (2010) sobre as interseções entre raiva, desprezo e compaixão na experiências de vítimas de assaltos a residências, em que o sentimento de impotência se transmuta em uma raiva que (ao contrário dos sujeitos cujos depoimentos são analisados por Katz) não consegue encontrar vazão em uma agressão física, dando assim lugar a dois sentimentos descritos na literatura especializada como "emoções de demarcação de status": o desprezo (Miller, I997) e a compaixão (Clark, I997).

Ainda no registro dos complexos emocionais, Miller (2000) analisa as relações entre medo, coragem e covardia. Tomando a imagem da guerra como expressão máxima da coragem, Miller examina uma série de fontes, na filosofia, na literatura e particularmente nas memórias dos combatentes, de modo a pontuar a conexão entre o medo e a coragem. Observa que a coragem nem sempre opera como um sentimento inversamente proporcional aos temores. O sentido da coragem está além da superação do medo, uma vez que ela é impulsionada por este sentimento, o que marca um ponto de congruência entre os corajosos e os covardes. Significa dizer que, assim como a covardia, a coragem atua com o medo e não após sua superação, o que desfaz a relação de oposição entre medo e coragem, à medida que se aproxima da noção de covardia. "O mesmo medo move cada um; apenas a tendência de ação é diferente” (Miller, 2000: 87).

Nostalgia e esperança parecem formar outro complexo emocional, cuja articulação tem em seu cerne a relação entretida com o tempo. É assim que a esperança surge em texto dedicado à nostalgia, como na passagem que escolhemos como epígrafe, e a nostalgia surge na análise da esperança "estagnada" que Crapanzano encontra entre os brancos na África do Sul nos últimos momentos do apartheid.

É essa relação subjetiva com o tempo, tingida por matizes emocionais distintos, que nos permite adentrar a esfera da relação entre sentimentos, tempo e política. Nestas considerações finais, apontamos brevemente a fecundidade analítica dessa relação para pensar diversos fenômenos contemporâneos da esfera política.

O primeiro fenômeno é o engajamento em movimentos sociais. A importância das emoções para explicar o envolvimento com uma causa vem merecendo recentemente a atenção dos cientistas sociais. Um investimento de fôlego pode ser encontrado na coletânea organizada por Goodwin, Polletta e Jasper (200I), em que os autores discutem três concepções da ação social - o ator interessado e calculista, o ator racional movido por princípios, o ator emocional movido por paixões - para advogar em favor da atenção para a dimensão emocional que move o engajamento em movimentos sociais, discutida a partir de um conjunto de estudos de caso que compõem a coletânea. No Brasil, recor- 
remos em outro lugar (Coelho \& Durão, 20I2) a essa matriz teórica para pensar especificamente o papel da esperança na atuação do Grupo Cultural AfroReggae (GCAR). Ali, discutimos duas oposições presentes em um conjunto de pequenas histórias (tratadas como fábulas) que o grupo conta sobre si mesmo: mártir/ sobrevivente e utopia/esperança. Mostramos, em nossa análise, que o grupo opta pelo sobrevivente para protagonizar suas narrativas sobre si mesmo, permitindo-nos assim "entender a ação social do GCAR como regida pelo sentimento de esperança, capaz de pautar a ação cotidiana em função de um futuro desejado e representado como tangível" (Coelho \& Durão, 201 2: 925).

Um segundo exemplo de fenômeno da vida política que pode também ser discutido com base em uma articulação entre esses sentimentos que jogam com o tempo é a propaganda política eleitoral. Brader (2006: I) discute algumas campanhas de propaganda política nas eleições presidenciais norte-americanas, analisando as implicações da opção pela instilação do medo ou pela incitação à esperança (e é importante assinalar a menção, ainda que breve, à presença de "sentimentos enterrados de nostalgia".

O papel da nostalgia é a chave analítica que orienta a coletânea já discutida de Angé e Berliner (20I5). Nela, um vasto conjunto de fenômenos políticos é analisado, como, por exemplo, a nostalgia do período imperial vivida pelos húngaros no contexto pós-socialista (Hann, 2015: 96) e a "experiência de imersão" dos visitantes de um parque inspirado num bunker soviético, na Lituânia (Lankauskas, 20I5: 35).

Em outro lugar (Oliveira, 2018), analisamos também a nostalgia como epicentro de uma "gramática emocional do exílio", tomando como base a composição dramática do personagem Henrik no romance As brasas, do escritor húngaro Sándor Márai. Na obra, o sentimento de desabrigo decorrente da quebra de fidelidade entre dois amigos caracteriza um tipo de exílio incorporado por uma dimensão temporal, no qual o personagem se perde no passado. No entanto, a nostalgia de Henrik não está restrita ao passado, mas aberta a ouvir novamente o amigo que regressa e reestabelecer algum grau de correspondência afetiva entre os dois. Trata-se de uma nostalgia vinculada à esperança de restituição afetiva.

Esse conjunto de exemplos nos estimula, assim, a sugerir a fecundidade desse arcabouço conceitual formado pelo entrelaçamento de emoções e tempo para a análise da vida política em múltiplas dimensões, de natureza mais ou menos explícita. Na política, a tese dos horizontes imaginativos fornece instrumental teórico particularmente fecundo aos estudos sobre os movimentos sociais e, em especial, sobre certa ordem dos sentimentos em período eleitoral, como observamos recentemente no Brasil. Considerando a experiência eleitoral, cabe uma reflexão sobre a cadeia de experiências e de informações, constituintes do processo de decisão do voto, e sua relação com o medo de uma possibilidade indesejada, do ponto de vista daquele que escolhe no presente o candidato que o representará no futuro. 
E o teor mais ou menos explícito é também um ponto digno de atenção, uma vez que o potencial dos sentimentos para mover o indivíduo à ação política - indo às ruas, subscrevendo petições, publicando, participando de debates em círculos mais íntimos ou em redes sociais e fazendo suas escolhas como eleitor -, se por um lado ainda pode exigir um certo trabalho de convencimento quanto à sua relevância junto aos cientistas sociais, por outro parece ser velho conhecido dos marqueteiros. Para atestar a relevância do problema, basta lembrar a polarização, de ostensividade talvez poucas vezes vista, entre o medo e a esperança na campanha para a presidência do Brasil em 2002, em que a atriz Regina Duarte engajou-se na campanha do candidato José Serra gravando uma fala em que dizia "ter medo do PT" e votar em José Serra porque ele "lhe dava segurança". A essa fala, opôs-se o jingle "Brilha uma estrela", da campanha de Luiz Inácio Lula da Silva, que dizia "sem medo de ser feliz (...) Lula lá, cresce a esperança".

Dezesseis anos depois, essa polarização se acirrou radicalmente nas campanhas presidenciais de 2018, momento em que os candidatos Fernando Haddad e Jair Bolsonaro apostaram no medo como linha mestra de seus discursos. Enquanto a propaganda de Haddad destacava os riscos da "violência política" e da "agressividade" presente nas posições controversas do adversário, a campanha de Bolsonaro disseminava o discurso da possibilidade de "retorno da corrupção" e a "ameaça de instauração de uma ditadura", ora "de esquerda", ora "comunista". A produção discursiva das campanhas incorporou um tom marcado pela prevalência do medo sobre a esperança, intensificando o "alerta" em relação ao que "pode acontecer", em caso de vitória eleitoral do oponente. O foco do embate se deslocou da esperança do benefício para o medo do malefício, movimento que tende a justificar as escolhas eleitorais mais pelo registro da rejeição do que pelo registro da aceitação. No mesmo processo eleitoral, cabe observar os movimentos sociais organizados pelas redes, nos quais as pessoas foram às ruas manifestar seus medos e expressar afeições e repúdios baseados na imagem de um temível porvir, tal como o "\#elenão".

Em tempos de polarizações extremas, em que tanto se fala sobre os riscos da "cultura do ódio" para o processo democrático, parece-nos crucial voltar a atenção das ciências sociais para o papel das emoções na política, resgatando-as assim do registro meramente instrumental que ocupam nas estratégias do marketing político e fazendo, do próprio marketing das emoções, ainda mais um objeto de sua reflexão. Esse arcabouço conceitual que delineamos aqui, articulando emoções, temporalidade e política com base nos sentimentos da nostalgia e da esperança, pretende oferecer um primeiro balizamento para essa agenda de pesquisa.

Recebido em I7/I/2019 | Revisto em 3/7/2019 | Aprovado em 29/10/2019 
Maria Claudia Coelho é professora titular do Departamento de Antropologia do Instituto de Ciências Sociais da Uerj. É doutora em sociologia pelo Iuperj e mestre em antropologia social pelo Museu Nacional/UFRJ. Suas principais áreas de interesse são a antropologia das emoções, as teorias da dádiva e as representações da violência. Dentre suas publicações, destacam-se O valor das intenções e A experiência da fama; a organização, apresentação e tradução de Estudos sobre interação; e diversos artigos em periódicos especializados, no Brasil e no exterior.

Eduardo Moura Pereira Oliveira é doutor e mestre em ciências sociais pelo Programa de Pós-Graduação em Ciências Sociais da Uerj. Professor do Departamento de Sociologia no Instituto de Filosofia e Ciências Sociais (IFCS-UFRJ). Suas principais áreas de interesse são a antropologia das emoções, as teorias da modernidade e as narrativas ficcionais. Publicou Teorias e práticas do poder como violência: reflexões a partir de Benjamin, Derrida e Agamben. 
1098

\section{NOTAS}

I Uma primeira versão deste trabalho foi apresentada no I 8 Congresso Mundial IUAES, realizado em Florianópolis, Santa Catarina, em julho de 2018.

2 A expressão é inspirada na ideia de Ramon Sarró (2009), quando pensa a antropologia como "a arte" de chegar "tarde demais", de "se atrasar". Ocorre quando os antropólogos entram em contato com sistemas tradicionais em vias de colapso e sentem certo arrependimento, dada a sensação de algo perdido no tempo.

3 Nessa e nas demais citações em idiomas estrangeiros, a tradução é nossa.

\section{REFERÊNCIAS BIBLIOGRÁFICAS}

Angé, Olivia \& Berliner, David (orgs.). (2015). Anthropology and nostalgia. New York/Oxford: Berghahn Books.

Berliner, David. (2015). Are anthropologists nostalgist? In: Angé, Olivia \& Berliner, David (orgs.). Anthropology and nostalgia. New York/Oxford: Berghahn Books, p. I7-34.

Brader, Ted. (2006). Campaigning for hearts and minds - how emotional appeals in political ads work. Chicago: University of Chicago Press.

Clark, Candace. (1997). Misery and company - sympathy in everyday life. Chicago/London: The University of Chicago Press.

Coelho, Maria Claudia. (20ıo). Narrativas da violência: a dimensão micropolítica das emoções. Mana, I6, p. I-20.

Coelho, Maria Claudia \& Durão, Susana. (2017). Introdução ou como fazer coisas com emoções. Interseções, I9/I, p. 44-6o.

Coelho, Maria Claudia \& Durão, Susana. (20I2). Moral e emoção nos movimentos culturais: estudo da "tecnologia social" do Grupo Cultural AfroReggae. Revista de Antropologia, 55, p. 899-935.

Coelho, Maria Claudia et al. (2013). Autoridade policial, riso e polidez: notas sobre interações entre polícias e cidadãos na Operação Lei Seca no Rio de Janeiro. Análise Social, 209 (XLVIII): 900-920. 
Crapanzano, Vincent. (2004). Imaginative horizons - an essay in literary-philosophical anthropology. Chicago/London: The University of Chicago Press.

Goodwin, Jeff; Polletta, Francesca \& Jasper, James. (200I). Passionate politics: emotions and social movements. Chicago: University of Chicago Press.

Hann, Chris. (2015). Why post-imperial trumps post-socialist: crying back the national past in Hungary. In: Angé, Olivia \& Berliner, David. (orgs.). Anthropology and nostalgia. New York/Oxford: Berghahn Books, p. 96-I22.

Katz, Jack. (2013). Massacre justo. In: Coelho, Maria Claudia (org.). Estudos sobre interação - textos escolhidos. Rio de Janeiro: Eduerj.

Lankauskas, Gediminas. (20I5). Missing socialism again? The malaise of nostalgia in post-Soviet Lithuania. In: Angé, Olivia \& Berliner, David. (orgs.). Anthropology and nostalgia. New York/Oxford: Berghahn Books, p. 35-6o.

Mauss, Marcel. (I980). A expressão obrigatória dos sentimentos. In: Figueira, Sérvulo A. (org.). Psicanálise e ciências sociais. Rio de Janeiro: Francisco Alves.

Miller, William Ian. (2000). The mystery of courage. Cambridge: Harvard University Press.

Miller, William Ian. (I997). The anatomy of disgust. Cambridge: Harvard University Press.

Oliveira, Eduardo Moura Pereira. (2018). A nostalgia em tempos de exílio: as gramáticas emocionais do reencontro no romance As brasas. Tese de Doutorado. PPCIS/Universidade do Estado do Rio de Janeiro.

Sarró, Ramon. (2009). The politics of religious change on the upper Guinea coast: iconoclasm done and undone. Edinburgh: Edinburgh University Press (International African Institute). 


\section{REFLEXÕES SOBRE O TEMPO E AS EMOÇÕES NA ANTROPOLOGIA: DEFINIÇÕES, PRÁTICAS E POLÍTICAS \\ Resumo}

Este trabalho propõe uma reflexão sobre as relações entre emoções, tempo e política, tendo como pressuposto a tensão entre as vivências subjetivas e a organização do fluxo da vida em passado, presente e futuro. Considerando a pluralidade de sentidos relacionados à experiência do tempo, exploramos os aspectos sociais e políticos ligados ao deslocamento das emoções das realidades imediatas, bem como as formas pelas quais os indivíduos entretêm relações afetivas com o tempo, revitalizando o passado ou imaginando o futuro de modo a engendrar formas de atuação política. $O$ trabalho está organizado em duas seções de revisão bibliográfica relativas à fecundidade analítica de dois sentimentos: a nostalgia, com base em Berliner (20I5), e a esperança, com base em Crapanzano (2004). Nas considerações finais, examinamos o rendimento heurístico do arcabouço conceitual delineado, apresentando algumas possibilidades de construção de objetos ligados às formas de atuação política.

\section{REFLECTIONS ON TIME AND EMOTIONS IN ANTHROPOLOGY: DEFINITIONS, PRACTICES AND POLICIES} and political aspects associated to the displacement of emotions from immediate realities and to examine the multiple affective relations individuals establish with time, revitalizing the past or imagining the future in order to elicit forms of political action. Its structure comprehends two sections dedicated each to bibliographical reviews of two feelings: nostalgia (based on Berliner, 20I5) and hope (based on Crapanzano, 2004). Final considerations approach issues concerning the analytical fruitfulness of the conceptual framework hereby outlined, presenting several possibilities to the construction of objects of research related to forms of political action.
Palavras-chave

Emoções;

tempo; esperança; nostalgia; emoções e política.

\author{
Keywords \\ Emotions; \\ time; \\ hope; \\ nostalgia; \\ emotions and politics.
}

